\title{
Coopetition within and between value networks - a typology and a modelling framework
}

\author{
Arash Golnam \\ School of Computer and Communication Sciences (I\&C), \\ Ecole Polytechnique Fédérale de Lausanne, \\ Station 14, CH-1015 Lausanne, Switzerland \\ E-mail: arash.golnam@epfl.ch \\ Paavo Ritala* \\ School of Business, \\ Lappeenranta University of Technology, \\ P.O. Box 20, FI-53851 Lappeenranta, Finland \\ E-mail: ritala@lut.fi \\ ${ }^{*}$ Corresponding author
}

\section{Alain Wegmann}

School of Computer and Communication Sciences (I\&C), Ecole Polytechnique Fédérale de Lausanne, Station 14, CH-1015 Lausanne, Switzerland E-mail: alain.wegmann@epfl.ch

\begin{abstract}
This study develops a typology of coopetition in value networks, wherein a distinction is made based on two factors. Firstly, whether coopetition takes place inside a particular value network (i.e., intra-value network coopetition) or between value networks (i.e., inter-value network coopetition); and secondly, whether the nature of collaboration is focused on value leveraging or value co-creation. We present empirical examples from the global ICT sector (Amazon Services, Amazon Marketplace, AIM Alliance, and Windows Mobile Community) to illustrate the four categories identified in the typology. Each example is graphically represented using a modelling framework in order to aid the understanding of various organisational and network structures that can accommodate coopetition as a complex inter-organisational relationship. We suggest that the developed typology and modelling methodology can help researchers and practitioners to better grasp and communicate the role and benefits as well as the network and organisational structures of coopetition within and between value networks.
\end{abstract}

Keywords: coopetition; networks; value; co-creation; leverage; typology; modelling, framework; ICT.

Reference to this paper should be made as follows: Golnam, A., Ritala, P. and Wegmann, A. (2014) 'Coopetition within and between value networks a typology and a modelling framework', Int. J. Business Environment, Vol. 6, No. 1, pp.47-68. 
Biographical notes: Arash Golnam is an Industrial Engineer by training and did his PhD in Management of Technology at École Polytechnique Fédérale de Lausanne (EPFL). Besides his research activities at EPFL, he is a Professor of Management Information Systems (MIS) and Systems Thinking at Business School Lausanne (BSL). He is a committee member of the international conference on exploring services sciences (IESS) and business modelling and software development (BMSD). His areas of research include conceptual modelling, system dynamics simulation, problem structuring and organisational decision making.

Paavo Ritala is a Professor at the School of Business, Lappeenranta University of Technology, Finland. His recent research interests are in the areas of inter-organisational networks, business models, innovation and coopetition (collaboration between competing firms). He has published on these topics in high-quality academic journals such as Journal of Product Innovation Management, British Journal of Management \& Technovation. He has also been involved in business practice with regard to these topics through his research, and in speaker and advisory roles.

Alain Wegmann worked for 15 years at Logitech in development (Switzerland, USA and Taiwan), manufacturing (Taiwan) and marketing (USA). In 1997, he became a Professor at École Polytechnique Fédérale de Lausanne (EPFL). He heads a laboratory that develops the systemic enterprise architecture method (SEAM); a method designed to work on business and IT alignment. SEAM is applied to define business and technical strategies, as well as business and IT services (ITIL compatible). SEAM is applied for teaching and consulting (http://lams.epfl.ch/reference/seam).

This paper is a revised and expanded version of a paper entitled 'Coopetition within and between value networks - a typology and a modelling framework' presented at EIASM 5th Workshop on Coopetition Strategy, Katowice, Poland, 13-14 September 2012.

\section{Introduction}

Coopetition - defined as the simultaneous occurrence of competition and collaboration within the same business relationship between horizontal actors (Bengtsson and Kock, 2000) - has attracted a great deal of attention in recent years in both research and practice. In analytical terms and for the sake of simplicity, coopetition has mainly been approached as a relationship between two (or few) competing firms, where the simultaneity of competitive and collaborative tensions and their implications have been under interest (e.g., Dowling et al., 1996; Bengtsson and Kock, 2000; Padula and Dagnino, 2007; Bengtsson et al., 2010).

Recently, research on inter-firm relationships has been increasingly shifted towards network or ecosystem levels of analysis - and coopetition research is no exception to this development. In fact, in line with the increasing focus on value networks and business ecosystems (e.g., Allee, 2000; Iansiti and Levien, 2004; Möller and Rajala, 2007), some recent work on coopetition have started to portray coopetition more and more as a relationship embedded in a larger network of actors. Such approaches include structural embeddedness and social networks (Gnyawali and Madhavan, 2001; Gnyawali et al., 2006; Ritala and Hallikas, 2012), mapping of competitive and collaborative linkages 
(Bengtsson and Kock, 1999; M'Chirgui, 2005), and assessing the level of coopetition in the industry-level (Choi et al., 2010; Rusko, 2011). The benefit of these approaches is in understanding the phenomenon of coopetition within the wider business environment in which the focal firm is embedded.

Despite these contributions, the vast majority of coopetition studies describe and analyse coopetition from the firm or relationship perspective. While such perspectives are valuable for firm-level strategy and individual relationship/alliance management, the potential for a more profound analysis of the role of coopetition in networks remains rather unexplored. In order to broaden the perspective from merely examining relationships between two firms that simultaneously compete and collaborate, we suggest that a network approach to coopetition is warranted. More particularly, we suggest that the concept of value networks can help in such analyses. Value networks are defined as a group of actors which are engaged into an exchange of both tangible and intangible resources in the attempt to jointly create value for the end customer and compete against other value networks by doing so (see e.g., Allee, 2000; Kothandaraman and Wilson, 2001).

To provide more systematic analytical tools to address the aforementioned research gap, in this paper we present an approach for modelling coopetition within and between value networks. Current research on coopetition is still short on providing concrete tools that can aid organisations to assess coopetitive relationships and explore the alternative designs of the value network structure capable of accommodating the complexities inherent in such a multi-faceted inter-organisational relationship. Doing so, requires a shift from a positivistic/theory building approach towards normative recommendations for initiating and sustaining coopetitive strategies and relations. Our research contributes to bridging this gap by developing a theoretically grounded modeling framework which is helpful to practitioners and scholars pursuing to understand the structure of the coopetitive value networks as well as their underlying objectives and challenges.

\section{Value network approach to coopetition}

Marketing, business, and strategy scholars have examined and analysed networks with a broad repertoire of partially overlapping concepts, including strategic networks (Gulati et al., 2000), business nets (Möller and Svahn, 2006; Möller and Rajala, 2007), value creating networks (Kothandaraman and Wilson, 2001), and value networks (Allee, 2000; Andersen and Fjelstad, 2003; Stabell and Fjelstad, 1998). All these concepts include the idea that firms do not operate in isolation, and that value creation should be analysed from a network, rather than firm-level perspective.

The reason underlying the choice of the word 'value' in the definition of value network comes from the fact that the companies that compose the value network provide superior customer value by utilising the resources, capabilities and competences of the value network (Kothandaraman and Wilson, 2001). Thus, customer value is delivered through a system consisting of various types of actors that contribute to the customer value either directly or indirectly (see e.g., Allee, 2000; Kothandaraman and Wilson, 2001; Pynnönen et al., 2011). In coopetition, customer value creation is an essential element, since in its absence coopetition can resemble a cartel-like collusive behaviour that may be harmful for customers and overall innovativeness (for discussion, see e.g., Gnyawali et al., 2008; Bengtsson et al., 2010). 
From the outset, the value network mindset has been an integral part of coopetition research. Brandenburger and Nalbuff (1996) put forward the concept of 'value net', where the role of the focal firm is analysed in the centre of a network consisting of customers, suppliers, competitors, and complementors. In this framework, it is suggested that any actor can take the role of either a competitor or a complementor, or that both roles may be acquired simultaneously. This provided the logic for coopetition as a simultaneous occurrence of both competitive forces, and complementing (i.e., collaborative) ones.

Recently, several scholars have drawn upon the value net-based perspective in analysing and illustrating coopetitive networks. First, value network approach has been explicitly used as a concept to illustrate and describe the logic of coopetition in a multi-actor environment within a given industry (see e.g., M'Chirgui, 2005; Rusko, 2011). Second, some studies have suggested conceptual approaches and implication to coopetition in network level of analysis. Dagnino (2009) describes how coopetition can represent either dyadic or network levels of analysis, and suggests that in the network level the value creating relationships typically embody more complex logic and relationship structure, which should be factored in the analyses of coopetition. Choi et al. (2010) present 'collective horizontal coopetition' as a level of analysis to discuss industry level initiatives involving many competing actors. In addition, another stream of coopetition research builds on conceptualising coopetition from a structural embeddedness perspective where the positioning of coopetition relationships within the overall network structure of the analysed actors (Gnyawali and Madhavan, 2001; Gnyawali et al., 2006; Ritala and Hallikas, 2012). Third, the current coopetition research recognises many cases in various industries where key industry players collaborate, affecting the structure and evolution of value networks [see e.g., Bengtsson and Kock, (1999) on Swedish rack and pinion and lining industries; Mariani (2007) on Italian opera houses; Ritala et al. (2009) on Finnish Mobile TV industry; and Gnyawali and Park (2011) on Sony and Samsung LCD-TV collaboration].

Based on the discussion so far, it can be concluded that value network approach to coopetition research is central and deemed indispensible in the analysis and conceptualisation of coopetition. However, explicit investigations still fall short of systematically explaining the logic of coopetition in value networks. In our view, analysis of coopetitive relationships in the network level could be rendered more beneficial if the value creation logic is clearly recognised, and analysed in parallel with the role of simultaneous collaboration and competition. Thus, based on the insights presented in this section, in the following we develop a typology for coopetition within and between value networks.

\section{Developing a typology for coopetition within and between value networks}

To analyse and develop a typology of coopetition in the value network level, we focus our analysis on two distinct aspects:

1 the scope of coopetition in value network(s)

2 the nature of collaboration. 


\subsection{The scope of coopetition}

In terms of scope of coopetition, we make a distinction between coopetition within the same value network and coopetition between different value networks. The former refers to the situation where coopetition takes place between the actors that operate in the same value network setting - that is - they provide value for same (or almost same) customer base to meet sufficiently similar customer needs. These types of settings happen when the coopetition relationship involves simultaneous collaboration and competition within the same domain. On the other hand, the latter setting refers to the situation where coopetition happens outside a single value network, which leads to the situation where competition and collaboration between 'coopetititors' is more separate. Such separation is suggested and is often referred to as a preferred mode of coopetition singe it allows more intuitive possibilities for collaboration and competition (e.g., Dowling et al., 1996; Bengtsson and Kock, 2000; Walley, 2007). However, we suggest that both types of situations - coopetition within and between value networks - do take place in practice.

\subsection{The nature of collaboration}

In terms of nature of collaboration, we consider two distinct processes: value leveraging and value co-creation. It is notable that these two value processes pursue different objectives and related strategies, and thus their analytical separation is important [see e.g., Möller and Rajala (2007) for discussion on different value logics of networks].

First, by value leverage refers to the seeking of synergies and complementarities between the resources, capabilities, and skills of different actors to create more customer value than if these assets were utilised separately. Value leveraging can thus be viewed as a group of coopetition motives pertinent to utilisation of complementary and supplementary resources (see e.g., Das and Teng, 2000; Dussauge et al., 2000; Ritala, 2012).

Second, by value co-creation we refer to collaboration with the aim of creating new products and services - and eventually new or improved sources of customer value. Various actors within the value network can participate in value co-creation, including customers, suppliers, and competitors (Möller and Rajala, 2007; Aarikka-Stenroos and Jaakkola, 2012). However, in this study we mostly focus on value co-creation between competitors. Coopetition, especially in technology intensive sectors, is often focused on these types of activities, where competitors collaborate to increase the size of the markets and to jointly create new offerings for the customer (see e.g., Ritala and HurmelinnaLaukkanen, 2009; Gnyawali and Park, 2011).

\subsection{A typology of coopetition within and between value networks}

Figure 1 summarises the typology, and identifies a typical motivation for coopetition complemented with one illustrative example in each value network setting. As illustrated, four types of coopetition can be identified depending on the scope of coopetition (i.e., inside a value network or between different value networks), or the nature of collaboration (value leveraging or value co-creation).

As shown in Figure 1, the underlying logic of value leveraging and value co-creation differs if the scope of coopetition is inside a particular value network (i.e., intra-value network coopetition) or between different value networks (i.e., inter-value network 
coopetition). When coopetition takes place inside the same value network, both competition and collaboration take place within the same domain and thereby forming the most intense form of coopetition (see e.g., Bengtsson and Kock, 2000). In competitive sense, the actors focus on the same set of end customers, and the collaboration between the different actors relies on utilising shared, value-network specific structures and processes, be they focused on bundling capabilities for synergy purposes or on creating new value. When coopetition takes place between different value networks, the actors leverage or co-create value by connecting two or several value networks together. In this situation, the competition takes place in a different domain than collaboration as the actors in coopetition compete for a certain market, but choose to collaborate in other [a coopetition logic called 'avoidance' in Dowling et al. (1996)]. Such situation can still be seen as coopetition since the actors compete and collaborate at the same time, but choose to do so in different domains.

Figure 1 A typology of coopetition within and between value networks

\begin{tabular}{|c|c|c|}
\hline \multirow{4}{*}{ 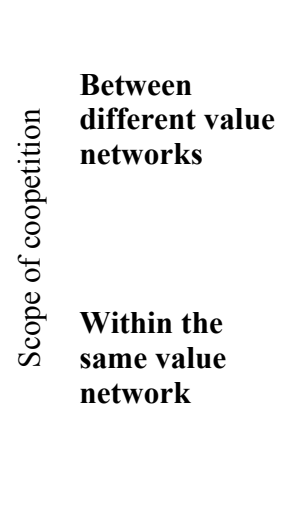 } & $\begin{array}{l}\text { Capability bundling between } \\
\text { competitors across structures } \\
\text { and processes of different } \\
\text { value networks } \\
\text { Example: } \\
\text { Amazon Services }\end{array}$ & $\begin{array}{l}\text { Capability building between } \\
\text { competitors across structures } \\
\text { and processes of different } \\
\text { value networks } \\
\text { Example: AIM Alliance } \\
\text { (Apple, IBM, Motorola) }\end{array}$ \\
\hline & $\begin{array}{l}\text { Capability bundling between } \\
\text { competitors utilising shared } \\
\text { structures and processes within } \\
\text { the same value network }\end{array}$ & $\begin{array}{l}\text { Capability building between } \\
\text { competitors utilising shared } \\
\text { structures and processes within } \\
\text { the same value network }\end{array}$ \\
\hline & $\begin{array}{c}\text { Example: } \\
\text { Amazon Marketplace }\end{array}$ & $\begin{array}{c}\text { Example: } \\
\text { Windows Mobile Community }\end{array}$ \\
\hline & Value leveraging & Value co-creation \\
\hline
\end{tabular}

\section{The modelling framework}

\subsection{Methodology: graphical modelling approach}

According to Simon (1992), one of the first steps in problem solving is to answer the question "How can the problem be represented to facilitate the solution?" Simon considers problem representation as the most crucial step, and the least understood in the problem solving process. The better the problem can be represented, the easier it is to understand it, as well as the potential solutions. Central to problem representation is the practice of modelling, and we suggest that technical and effective problem structuring method should be model-based (Rosenhead and Mingers, 2001).

A model is a representation of a part of 'reality' as perceived by the people who want to use it to understand, to change, to manage and to control that part of perceived 'reality' (Pidd, 2003). Modelling is defined as constructing systems that account for some aspect of the domain to be investigated (Klir, 1991). Models are simplifications, abstractions of those aspects of the perceived 'reality' that are deemed to be important by the modeller. 
Pidd (2003) refers to models as 'tools for thinking' that are used to add leverage to human thought and analysis.

The models employed to structure problems should be facilitative devices that enable dialog between the participants to a decision making initiative who intend to act upon it. Therefore, a model is a means of representing the problem structure. A modelling method should therefore serve to communicate or 'connect' cognitively with a given group of participants in the decision making process. In order for this to happen, the models representing the problem structure should be easily understood by the decision makers and should be cognitively accessible to decision makers from a range of backgrounds without requiring special training (Mingers and Rosenhead, 2004).

Graphical representations, in particular graphical models and diagrams, are more cognitively effective than other forms representation such as sentential or verbal representations in conveying both qualitative and quantitative information of a complex nature (Larkin and Simon, 1987; Tufte, 1990). Diagrams facilitate problem-solving by assembling all pieces of information and thereby reducing the time required to make inferences. They also facilitate the representation, communication and discussion of causal assumptions. When employed in problem structuring, a diagram can be referred to as an evolving thinking tool. It can represent an individual's qualitative understanding of a problem situation through the linkages between the decision elements and clarifies ambiguities by communicating the assumptions held by the individuals back to them, eventually leading to a well-defined and commonly understood problem definition (Lane, 2008).

Based on these insights, we chose to utilise graphical modelling methods in examining coopetition settings in value networks, as outlined in our typology. The modelling framework presented in this paper is part of the systemic enterprise architecture method (SEAM) (Wegmann, 2003).

\subsection{Modelling coopetitive value networks}

In this section, we describe the overall modelling framework and specify the nature of the modelling constructs and representations.

In our modelling framework we represent a hierarchy of nested systems, market segments, value networks and organisations (see Figure 2). As shown, we start by modelling a market segment. A market segment can be decomposed to its sub-systems. In our modelling framework we decompose a market segment to view the competing value networks as its constituent sub-systems. In Figure 2, the 'market segment' consists of 'value network A' and 'value network B'. As we decompose a system we see the entities within it (such as the value networks within a market segment); we call this representation the white-box view of the system. On the contrary, when the sub-systems that compose a system are not modelled, we view the system as a black-box. In our models, the white-box and black-box view of a system (i.e., value network, organisation and department) is colour-coded with white and black respectively.

In Figure 3, we model two value networks within a market segment capturing the relationships between the entities. We shortly explain the notation used in the study here by using the above example:

- As illustrated, 'value network A' competes with 'value network B'. In the model, a line annotated with 'competition' denotes this competition. 
- In 'value network A', 'organisation A, B and C' collaborate. A diamond connected to the organisations with solid lines indicates that this collaboration is value cocreation by nature.

- In 'value network B', 'organisation E' collaborates with 'organisation D'. We can also see that 'department $\mathrm{X}$ and $\mathrm{Y}$ ' are the constituent elements of 'organisation $\mathrm{D}$ '. As shown, a solid line connects 'organisation E' to the diamond that is connected to 'organisation D' by a dashed line. This denotes that the nature of the collaboration is value leveraging. Meaning that 'organisation E' leverages value to provide 'organisation D' with the resources and capabilities it requires to sustain its value creation activities.

- The line annotated with 'affiliation' that connects 'organisation E' to 'organisation C' denotes that 'organisation E' is affiliated with 'organisation C'. This could mean that the two organisations belong to one entity or 'organisation E' is a subsidiary of 'organisation C'.

Figure 2 The hierarchy of systems in the modelling framework

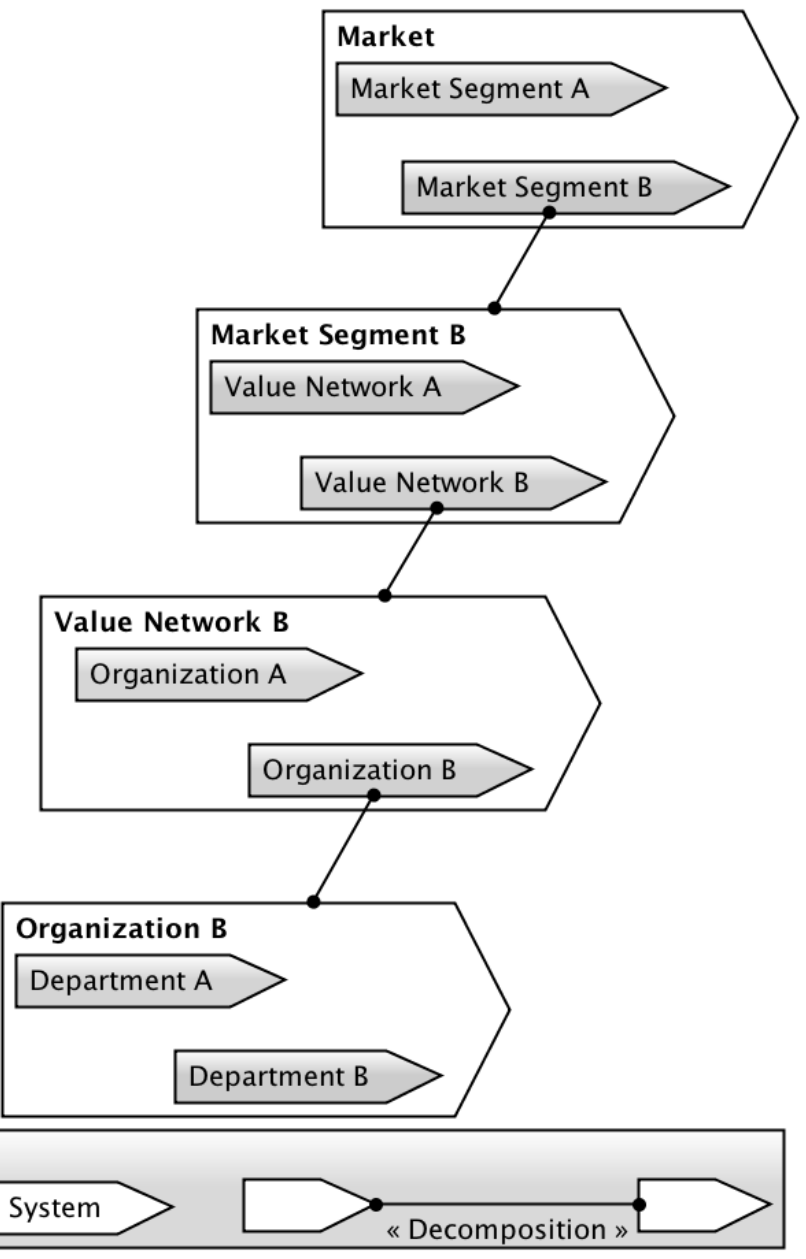


Figure 3 The nature of the relationships on the modelling framework

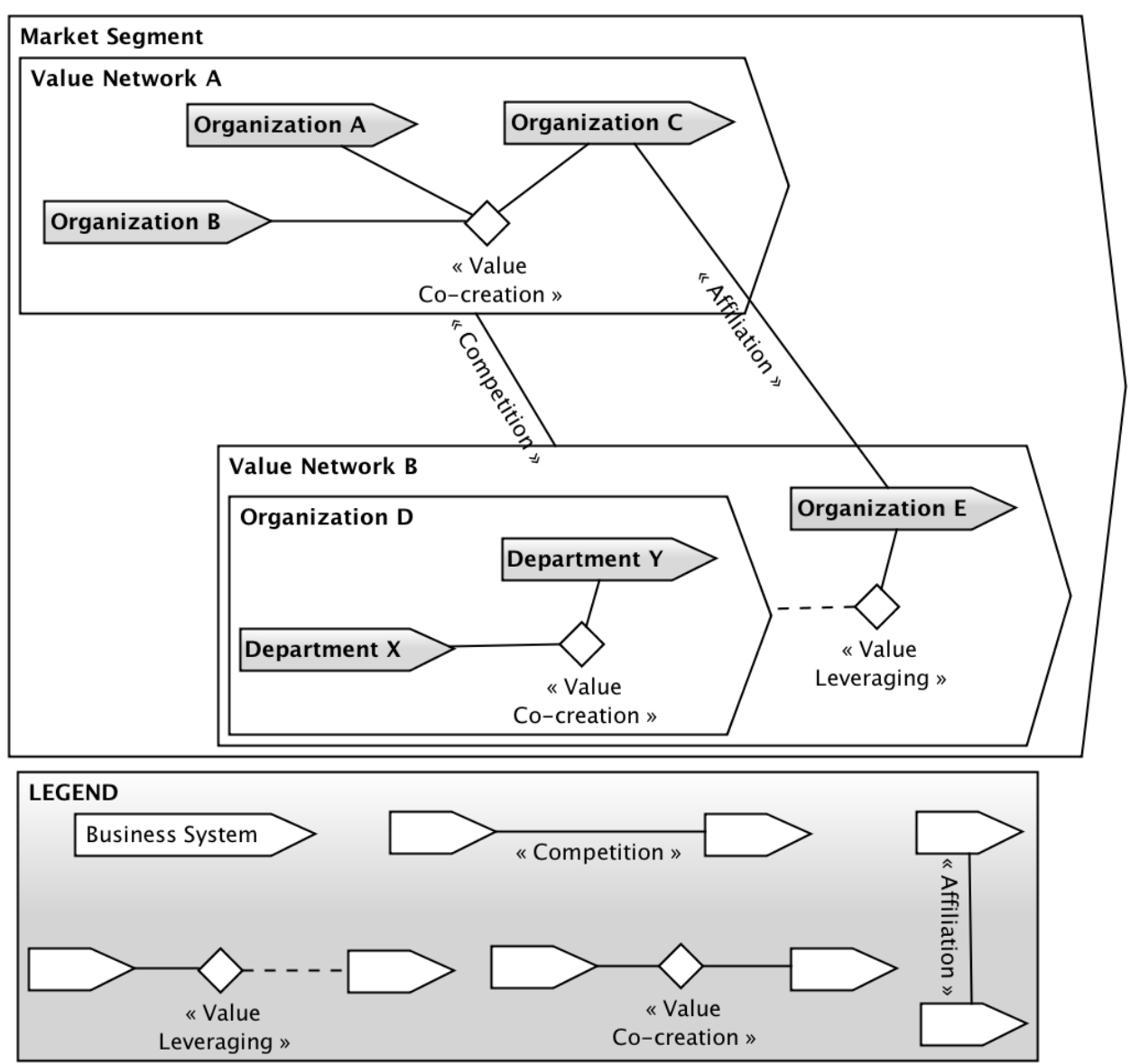

In the following sections, we discuss four specific case examples of coopetition from value network perspective. The selection of the case examples represents purposeful sampling using descriptive case studies (see e.g., Yin, 2003). Our purpose is to describe how the cases appear from the standpoint of the developed framework in a compact and approachable way. Firstly, to the best of our knowledge, the coopetition instances discussed in this paper are not addressed or referred to in the coopetition literature. Thus, for instance by bringing up the example of Amazon Marketplace and Amazon Services we would like to highlight the coopetitive nature of Amazon.com growth strategies that are mainly glossed over in the coopetition research community. Secondly, the four examples explored here provide a suitable configuration with respect to the typology of coopetition developed in the paper. Finally, the nature of the coopetitive relationship explored in the cases enables the illustration of the modelling constructs and the notational elements embedded in our modelling approach. 


\subsection{Modelling coopetition in Amazon Marketplace value network}

We now apply the modelling framework to represent the example of Amazon Marketplace. In this coopetitive value network the nature of collaboration is value leveraging and the competition takes place within the value network.

As illustrated in Figure 4, 'Amazon Marketplace value network' and 'Barnesandnoble.com value network' are in competition in the 'Online Books market segment'. For the sake of simplicity other competing value networks within this segment are not modelled. In addition, as we are interested in modelling coopetition in 'Amazon Marketplace value network', we do not represent the entities within 'Barnesandnoble.com value network' and thus this value network is represented as a black-box.

Figure 4 Coopetition within Amazon Marketplace value network



Inside 'Amazon Marketplace value network', Amazon.com is modelled as white-box. Thus, we can see the various departments within Amazon.com such as 'information technology', 'customer relations management' and 'logistics and fulfilment' and 'books' that collaborate to co-create value. It is also shown that 'Amazon.com' collaborates with 'bookstore A' and 'bookstore B' within the Amazon Marketplace. As a result of this collaboration the bookstores are able to place their books next to the ones from Amazon.com's on the same product page. This means the customer can either buy from Amazon.com or from the small independent bookstores that are present on the Marketplace. Thus, Amazon.com's books department is in a head-on competition with the bookstores on Amazon Marketplace to win customer orders. The line annotated with 'competition' denotes this competition. The dashed line connecting Amazon.com to 'bookstore A' and 'bookstore B' indicates that Amazon.com provides these entities with the supplementary and complementary resources they require to create value for the customers within the segment and thus the nature of the collaboration is value leveraging. 
The simultaneous existence of the competition and collaboration linkage implies the coopetitive relationship between these entities.

Amazon.com's coopetition with bookstores in the Amazon Marketplace led to the generation of significant business and thereby considerable increase in net sales and gross profit thus helping Amazon.com to offset operating expenses and achieve profitability in 2003 for the first time after its establishment. Amazon reported that third-party transactions accounted for $20 \%$ of its North American units sold in the second quarter of 2002. In 2010, Amazon Marketplace accounts for over 35\% of Amazon.com's revenues (Amazon, 2011; Brandt, 2011). It can be concluded that with the help of coopetition, in a matter of a few years Amazon managed to move from being on the brink of bankruptcy to becoming a world-class e-tailer with the largest online store available.

This type of value network structure utilising coopetition is not only beneficial to Amazon.com. In fact, it has been particularly beneficial to small bookstores - prior to their online presence at Amazon Marketplace, they were having a tough time competing with Amazon.com and the book superstores such as Barnes and Noble and Borders. The period between 1993-1996 marks the launch of Amazon.com and the over 450 openings of book superstores with Barnes and Noble and Borders accounting for 348. Within the same period, over 200 independent bookstores went out of business (Brandt, 2011). Amazon Marketplace gave these booksellers the opportunity to present their offerings to millions of potential customers. Thus we can assert that this coopetition increased the competitiveness of coopetitive actors against other value networks through synergy and efficiency benefits.

The main challenge inherent in this coopetition is the tension that arises between the players due to their co-existence in the customer end. However, based on Amazon.com's annual reports including third party sellers has been seen as an integral part of Amazon.com business model over time, and therefore this challenge has been turned to a positive growth story (Amazon.com Investor Relations, 2011).

\subsection{Modelling coopetition between Amazon.com and Borders.com value networks}

In April 2001, Amazon.com made an agreement with Borders, one of its fiercest competitors, to launch and power Borders' online operations on Borders.com. Based on the agreement, Amazon.com provided Borders with an e-commerce solution of technology services including inventory, fulfilment, site content and customer service in order to help Borders establish online operations. Such services were offered through Amazon.com Services, a subsidiary of Amazon.com, which offers a variety of e-commerce services for other retailers (van Heck and Vervest, 2007).

In Figure 5, we model the coopetition between Amazon.com and Borders.com. 'Amazon Services' provides to 'Borders Books' the resources it requires to launch its online operations in 'Borders.com value network'. However, while Amazon.com cooperates with Borders through its subsidiary 'Amazon.com services', 'Amazon Marketplace value network' and 'Borders.com value network' directly compete in the 'Online Books market segment'. It is interesting to observe that in this model Amazon.com is involved in intra-value network coopetition with the bookstores and inter-value network coopetition with Borders.com. In both coopetition initiatives the nature of collaboration is value leveraging. This increased the competiveness of 
coopetitive actors operating in different value networks through leveraging of certain players' capabilities to gain synergy and efficiency benefits.

Figure 5 Coopetition between Amazon Marketplace and Borders.com value network

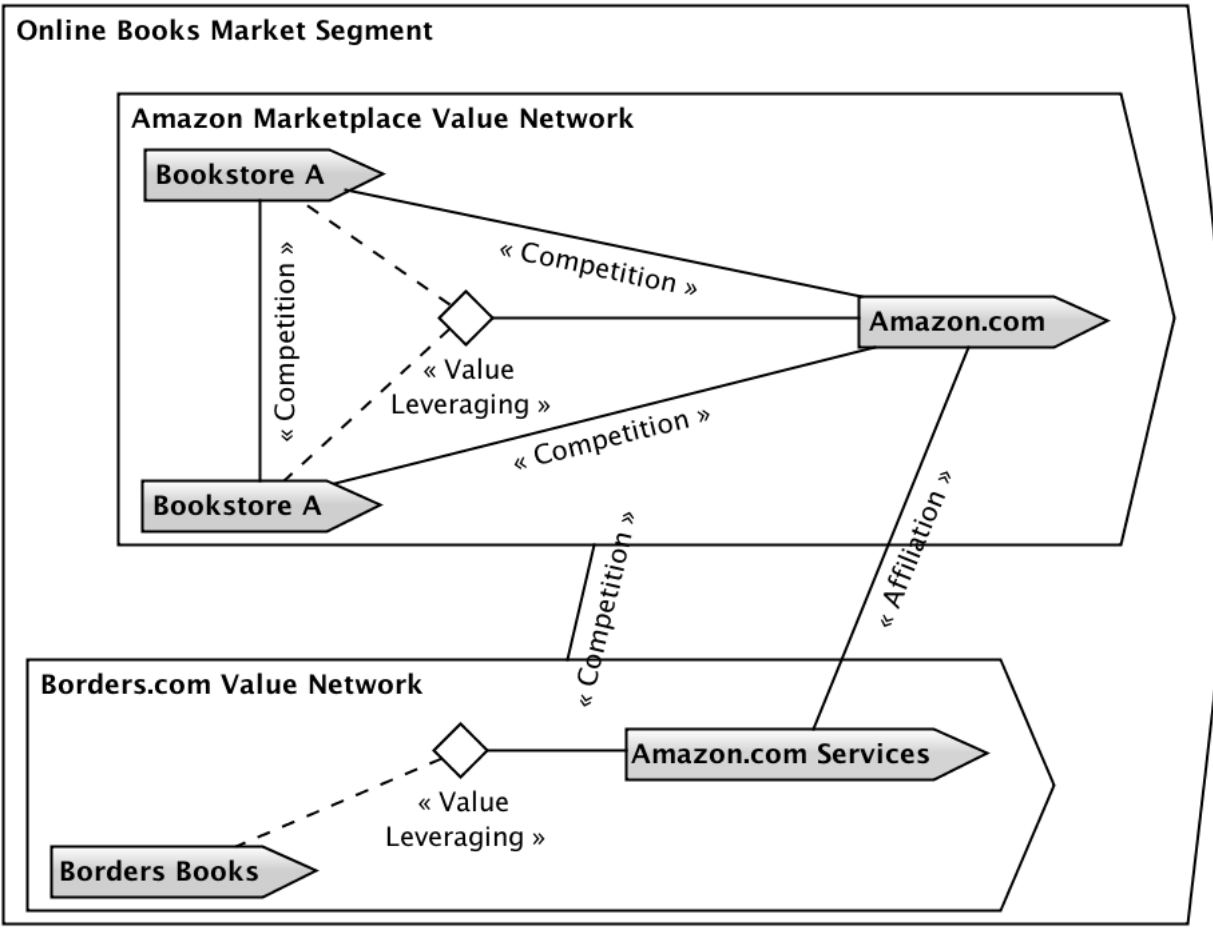

Two main challenges can be identified with respect to this coopetition type. The competing customer, Borders.com, may face the risk of lock-in as it relies on the services offered by a competitor. In service provision such risks are mainly addressed by service level agreements (SLAs) between the service provider and the service client. There exists a potential challenge on the supplier side as Amazon.com is empowering a customer who is a competitor. In a recent interview (Levy, 2011), Jeff Bezos points to controversies surrounding the decision to provide e-commerce service to competing companies and explains Amazon.com's vision of becoming the 'Earth's most customer-centric' company stressing that, unlike most companies, Amazon focuses on the customers rather than the competitors.

\subsection{Modelling coopetition between the developers in the Windows Mobile Community}

In Figure 6, we represent the Smart Phone application market segment in which the 'Android value network', 'iTunes value network' and the 'Windows phone value network' are in direct competition. In these value networks, Google, Apple and Microsoft offer free tools, sample code, community support, and educational resources to help developers develop apps and games for their mobile platforms. This has been widely 
called as war between mobile 'ecosystems' in the popular press (for discussion, see also Gueguen, 2009).

Figure 6 Coopetition within the developers in the Windows Mobile Community

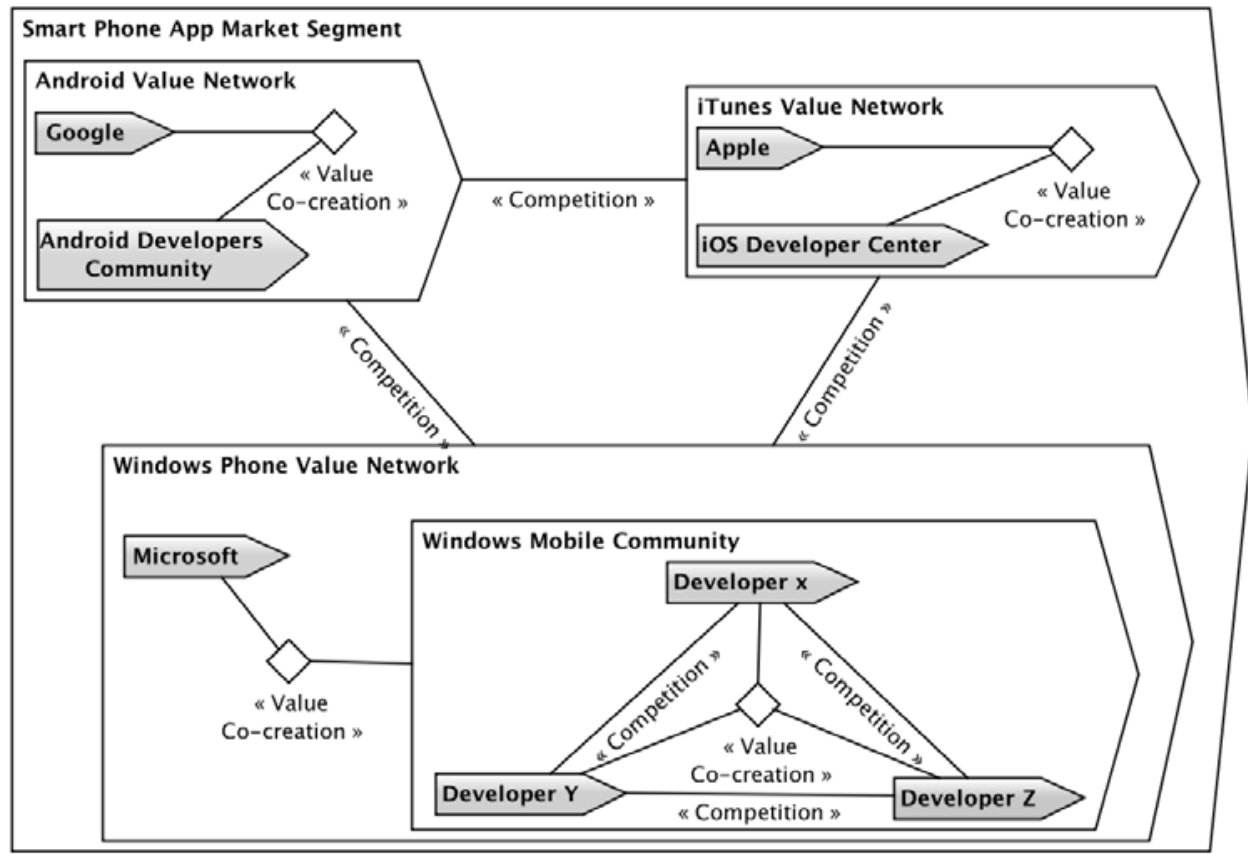

The nature of the collaborative relationships within these communities (i.e., value networks) is value co-creation, since the aim is to develop new and improved solutions to meet end customers' needs. Within these communities the developers collaborate by expanding the number of the applications and thus making the platform more competitive relative to the competing platforms (i.e., expanding the relative value of a particular platform against other platforms). At the same time they compete for the customers who want to buy an application from their platform (i.e., competing for the scarce resources and attention of the customers). This logic is in line with the one often suggested by coopetition researchers: 'a business pie' is first increased through collaboration, and the actors compete to divide it up (Brandenburger and Nalebuff, 1996; Ritala and Hurmelinna-Laukkanen, 2009).

In Figure 6, we have modelled this inter-value network pattern of coopetition in the 'Windows Mobile Community'. The rest of the application developer communities are modeled as black-boxes. Main competitive objective of this type of a community is to increase competitiveness of coopetitive actors against other value networks through innovation and new market creation. There may be some challenges in steering the value network towards common goals, since the goals of individual actors may be only partially convergent, and sometimes even conflicting. However, in markets where network effectsbased are available (such as in the example discussed here), the coopetition is likely to follow a positive-sum logic (e.g., Ritala and Hurmelinna-Laukkanen, 2009). 


\subsection{Modelling coopetition between Apple and IBM in the AIM Alliance}

In this section, we model the coopetition between Apple and IBM in the AIM (Apple, IBM and Motorola) alliance that designed and manufactured a new generation of microprocessors with reduced instruction set computer (RISC) architecture. The AIM Alliance gave birth to PowerPC (i.e., performance optimisation with enhanced RISC - performance computing, sometimes abbreviated as PPC) (see e.g., Duntemann and Pronk, 1994; Vanhaverbeke and Noordehaven, 2001).

Apple, IBM and Motorola established the Somerset Design Center in Texas to develop the RISC-based CPUs. The facility was jointly owned and managed by IBM and Motorola and employed more than 350 engineers, of which 50\% were working for IBM and $50 \%$ for Motorola. Apple also kept a number of staff in the facility to ensure software compatibility. The design centre was co-directed by IBM and Motorola (Duntemann and Pronk, 1994).

Figure 7 Coopetition between Apple and IBM in AIM Alliance

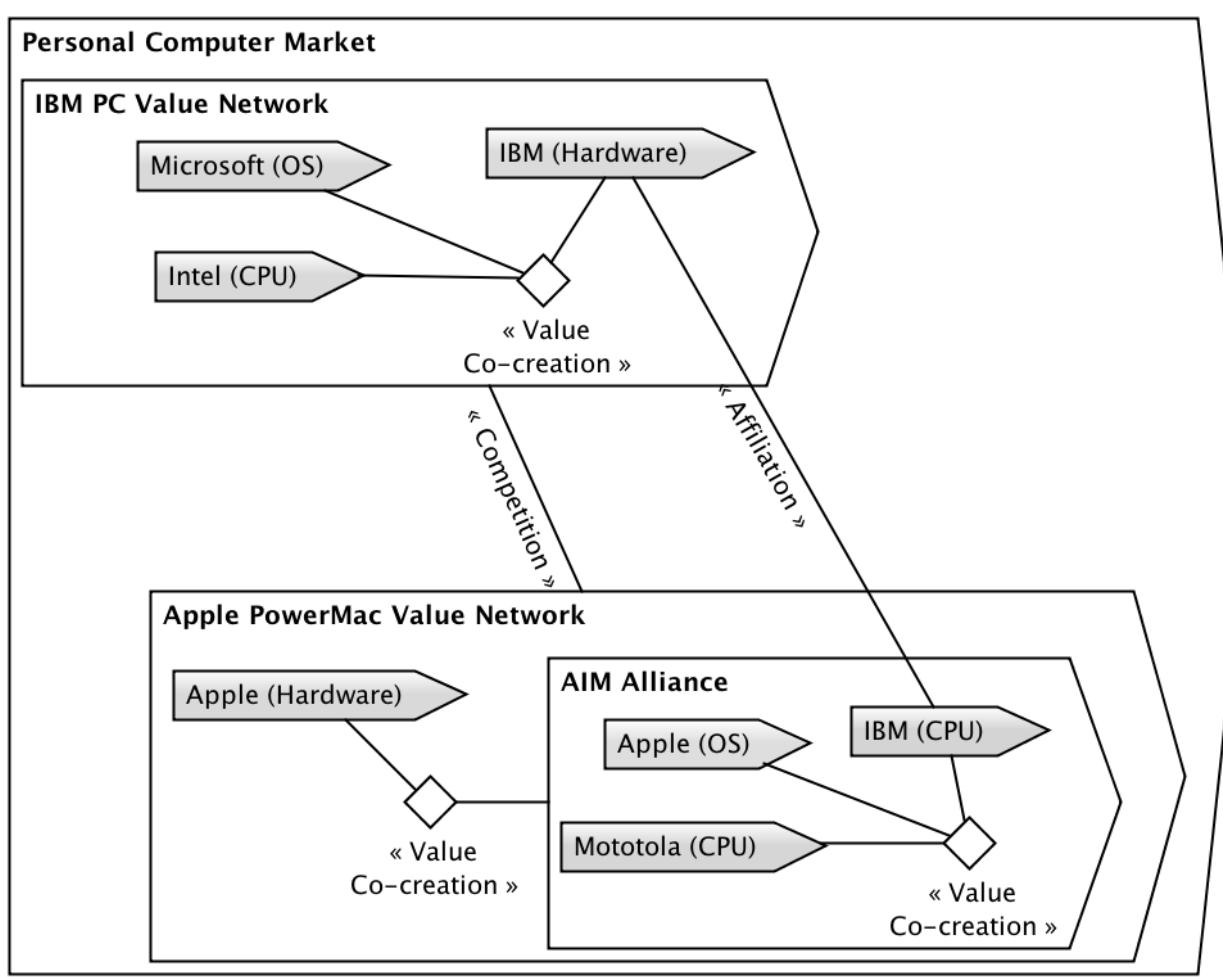

Figure 7 models the PC market circa 1994, representing the 'IBM PC value network' and 'Apple PowerMac value network'. In the Apple value network we represent the AIM Alliance as a white box modelling the collaboration between IBM, Apple and Motorola. We have specified the role of the companies in parentheses. IBM and Motorola were focused on the development of the RISC CPU and Apple was in charge of ensuring the compatibility with the operating system and the third party applications. The line connecting IBM (CPU) to IBM in the AIM Alliance implies that the companies belong to 
the same financial entity. Hence, while Apple and IBM compete in the PC Market as designers and manufactures of personal computers, Apple as an OS developer is cooperating with IBM as CPU designer and manufacturer.

The main objective of the alliance was to increase competitiveness of coopetitive actors operating in different value networks through innovation and new market creation and thus to prevent Intel and Microsoft from controlling the future of the CPU architecture and OS in desktop computers.

The PowerPC 601 was the first generation of RISC microprocessors developed by AIM. The design effort started in mid-1991 and the first prototype chips were available in October 1992. The first 601 processors were introduced in first Apple Power Macintoshes, later known as Power Mac, on March 14, 1994 (Duntemann and Pronk, 1994; Carroll and Reader-Adams, 1994). The RISC-based Macs received favourable reviews for their speed and excellent compatibility with existing Mac software and hardware and helped Apple capitalise on its newfound price/performance lead to expand its market share.

When Apple first announced its intention of designing its next generation of Macintosh machines based on the PowerPC in 1991, no native software existed for this platform. In 1993 less than a year before the launch of the RISC-based Macs, fewer than a dozen applications were expected. By January 1994, more than 60 developers had announced they would have PowerPC applications available before the first Power Mac shipped and the number of native applications continued to increase weekly afterwards (Duntemann and Pronk, 1994; Carroll and Reader-Adams, 1994; Linzmeyer, 2004).

There were challenges as well. As Apple and IBM were competitors, a major issue for the companies was to prevent the leakage of confidential information and know-how that could result in or the risks of technological imitation.

\section{Synthesis and findings}

In Figure 8, we integrate the four models and the initial typology presented at the beginning of the paper. For the sake of simplicity we have modelled a maximum of two organisations within each value network.

\subsection{Coopetition within the same value network}

In the models that represent the coopetition within the same value network, it can be observed that the value network within which coopetition exists is always competing with another value network in the market segment. This implies that intra-value network coopetition helps organisations expand their market share and gain competitiveness against the competing value networks. This is in line with coopetition research suggesting that firms collaborate with their competitors to be able to compete even more fiercely against the rest (Lado et al., 1997), as well as support favourable technological trajectories and other business-related interests in the network-against-network competition (Gomes-Casseres, 1994; Choi et al., 2010; Ritala, 2012). The Amazon Marketplace example shows how the bookstores included in this value network pursue to increase their competitiveness against other players (here: Barnes and Noble). On the other hand, the coopetition within Windows Mobile Community is an archetypical example of technology ecosystem battles that are quite frequent in the ICT industry (see 
also Gueguen, 2009). These types of coopetition initiatives may be quite intensive, since here the locus of competition is within the same value network, and thus the collaborating actors are competing within similar-or nearly-similar logics (such as in Amazon Marketplace and Windows Mobile Community cases). The resulting coopetition tension is therefore high, and creates potential challenges in terms of the management of coopetition.

Figure 8 A Synthesis of the models representing the typology of coopetition

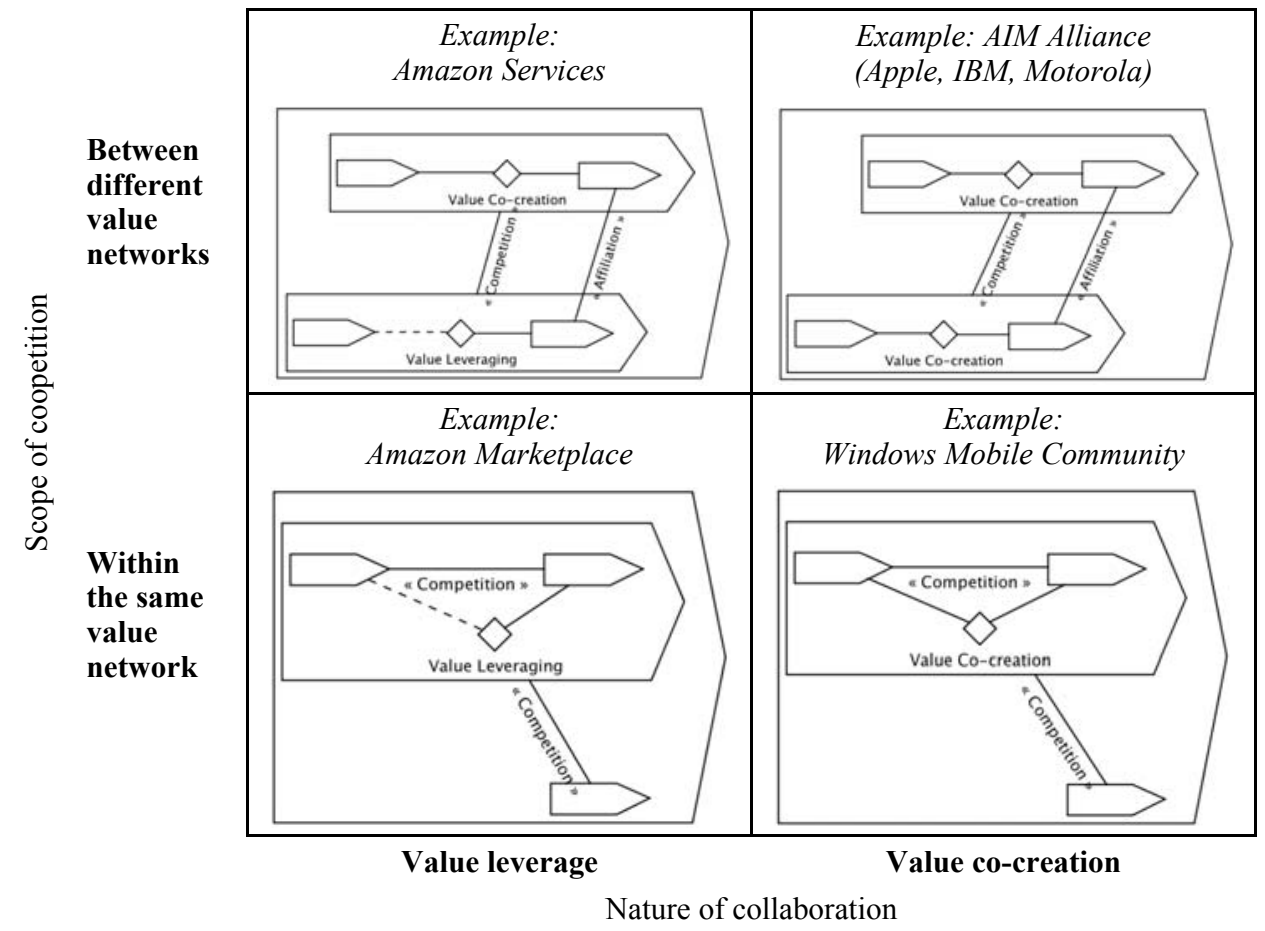

\subsection{Coopetition between value networks}

The models that represent coopetition taking place outside the value network (both for value leveraging and co-creation collaboration) share the 'Affiliation Linkage'. This means that a coopetitive entity that is in collaboration with another organisation belongs to a competing value network. This finding is in line with the research conducted by Dowling et al. (1996). According to them, companies have two basic choices for dealing with coopetition: avoidance or adaptation. In terms of the latter, Dowling et al. suggest that organisations should departmentalise or divisionalise their organisational structure so that different departments deal with different aspects of the multifaceted relationships [this is also suggested by Bengtsson and Kock (2000)]. As illustrated in the case of the AIM Alliance and Amazon Services each of the main players (Apple, IBM and Amazon.com) established separate entities that comprised some divisions from their organisational structure. Thus, it can be concluded that such arrangement is a way to achieve an organisational structure capable of addressing the challenges and the complexities inherent in a coopetitive relationship. The results thus complement the 
suggestions that management of coopetition is easier if collaboration and competition can be separated to some extent in the organisational structure (Bengtsson and Kock, 2000; Walley, 2007). This type of coopetition may also be less intensive when compared to the instances where it takes place within value networks, since there may be more clear ways to separate and manage collaboration and competition tensions if the firms operate within different value networks.

\subsection{Summary of implications of the typology}

Figure 9 summarises the discussion so far in terms of underlying value network logic, as well as the main objectives and challenges related to the four settings of coopetition modelled. Value network logic is related to the identified logics based on typology, while main competitive objectives and challenges utilise the insights gained from the case examples modelled in this paper.

Figure 9 A typology of coopetition within and between value networks - summary

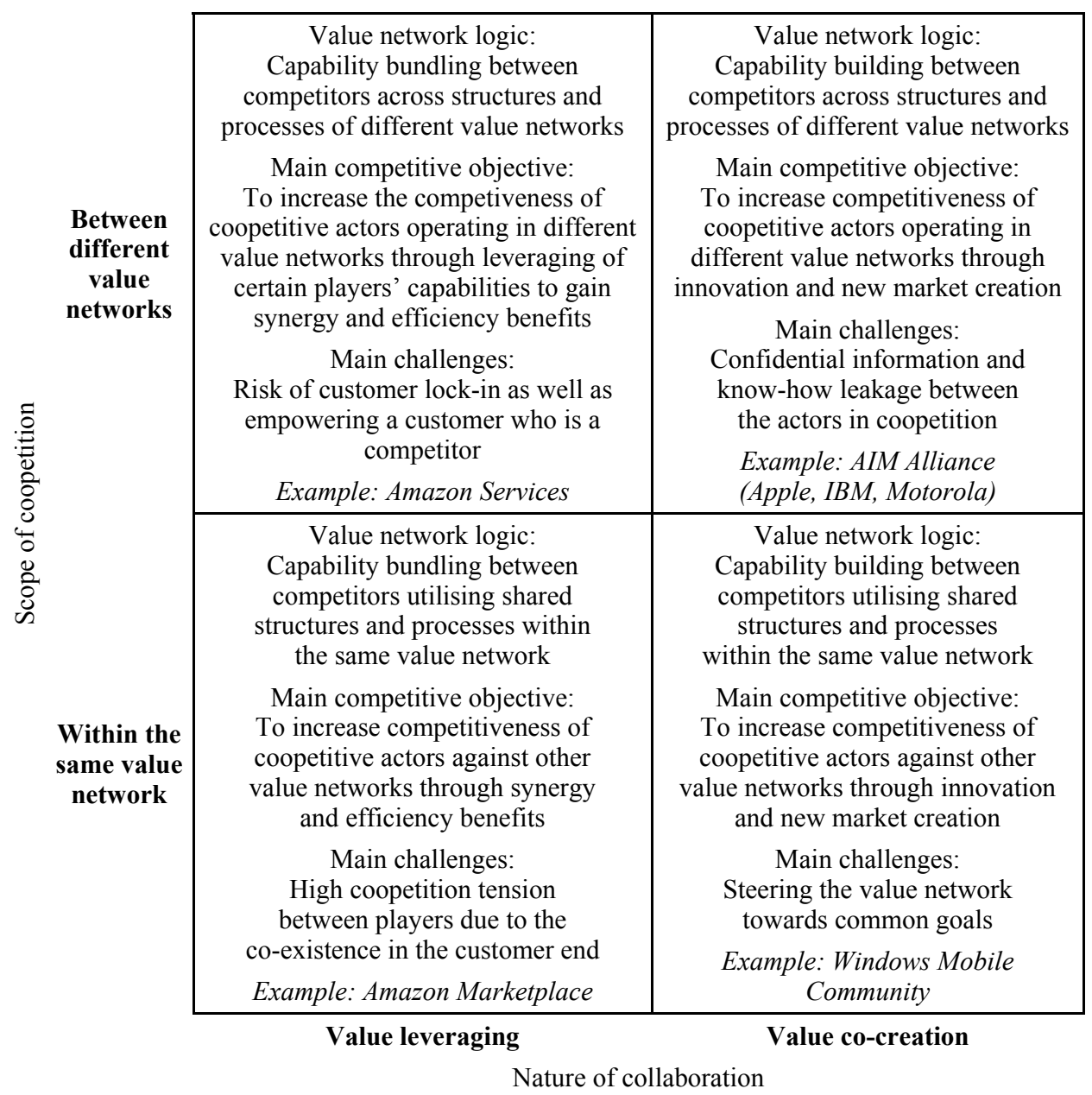




\section{Discussion and implications}

This study has presented a typology of coopetition within and between value networks. We illustrated the practical relevance of the typology with four analytical models. The aim of the paper is to introduce a modelling framework that can provide analytical assistance in understanding the logic of coopetition within value network context. There are several theoretical and practical implications, as well as some limitations related to this study, which will be outlined in the following sections.

\subsection{Theoretical implications}

The main theoretical contributions of this paper are twofold. Firstly, we have presented a typology of coopetition within and between value networks that can be utilised to understand the nature or collaboration and the competition in coopetitive value networks. The typology provides a platform which can help to analyse coopetition from many types of approaches, including strategies, value network configurations, and industry analyses. This study has pinpointed particular motivations, benefits, and challenges related to these settings, but the approach can be used in other settings as well. Especially useful insights for coopetition theory come from the distinctions in the typology between the value logic of collaboration, as well as the scope of coopetition. In terms of the collaboration, value leveraging and value co-creation can be seen as separate but not mutually exclusive motivations of coopetition. Understanding their both roles in the value network settings can enrich the analyses on coopetition motives, in particular the capability-based considerations. With respect to the scope of coopetition, this study suggests a difference when the firms in coopetition use the structures and processes of the same value network, or utilise structures and processes across value networks. The first option relates to involving competitors within a certain firm's value network (as in the case of Amazon Marketplace or Windows Mobile Community), while the former option can utilise processes across value networks (as in the case of Amazon Services or AIM Alliance). If the locus of competition is inside the same value network of the players that cooperate, the tension of coopetition is likely to be higher compared to the case when competitors operate in different value networks. This issue affects the role and dynamics of competition in coopetition analyses, and thus definitely deserves further inquiry.

Secondly, we have introduced a modelling framework to represent the four types of coopetitive value networks. The models and their elements can be used as concrete tools to visualise and analyse coopetition in different value network settings. The models are designed to serve as learning devices and thinking tools, which can enable the decision makers to refine their thoughts and build confidence in their views when it comes to designing the network structure in coopetitive initiatives. More importantly, the representations generated using this modelling framework can serve as proofs of concepts for showing the possibility of designing the network structure capable of addressing the challenges inherent in coopetition. In addition, the models could be combined with more detailed value creation and capture analyses used in value network literature (e.g., Allee, 2000; Pynnönen et al., 2011), thereby shedding more light on the incentives behind the development of coopetitive initiatives. 


\subsection{Practical implications}

The study includes many practical implications, since it presents a clear typology and a modelling framework that can be used to visualise and analyse various coopetition settings. Moreover, the modelling framework can help management practitioners in structuring choice situations in terms of the organisational and value network design that can accommodate the complexities inherent in coopetition. Exploring the structure of coopetition within and between value networks can also shed light on the incentives behind coopetition, and serve to effectively communicate the alternative designs to various internal and external stakeholders. For instance, the three linkages introduced in the modelling framework (i.e., collaboration, competition and affiliation) can facilitate the understanding and identification of the coopetitive relations within and between value networks in which the firm is embedded. In doing this, the modelling framework could be used in group model building sessions and workshops within organisations to elicit and explore possible design choices to accommodate the complexities and mitigate the potential risks associated with coopetition.

\subsection{Limitations and future research}

The typology and the modelling approach presented here aims to be generic to any coopetition setting, but there are several limitations related to our study that should be acknowledge. First, we focus mainly on value creation, and do not explicitly analyse value capture or appropriation that eventually takes place through the competitive process between different actors in coopetition relationships. This issue has been explicitly been put forward in the coopetition research (e.g., Walley, 2007; Ritala and Hurmelinna-Laukkanen, 2009), and definitely warrants further attention in future research. Second, our approach simplifies coopetition settings into four-cell typology, and real-life business situations may not clearly fall within one category only, or in extreme case in any of these categories. Thus, the reductionist approach adopted here certainly poses limitations for interpretation and analysis. While this is a limitation, we suggest that this can be taken into account in analysing and modelling coopetition relationships. In fact, by initially acknowledging the different logics of coopetition separately, it is easier to start analysing more complex value network settings. In any case, we suggest that research using deliberately more complex approaches is also needed to pinpoint the detailed scenarios, which may take place in networked coopetition settings.

\section{References}

Aarikka-Stenroos, L. and Jaakkola, E. (2012) 'Value co-creation in knowledge intensive business services: a dyadic perspective on the joint problem solving process', Industrial Marketing Management, Vol. 41, No. 1, pp.15-26.

Allee, V. (2000) 'Reconfiguring the value network', Journal of Business Strategy, Vol. 21, No. 4, pp.36-39.

Amazon.com Investor Relations (2011) Annual Reports and Proxies [online] http://phx.corporateir.net/phoenix.zhtml?c=97664\&p=irol-reportsannual (accessed 26 June 2011). 
Andersen, E. and Fjelstad, Ø. (2003) 'Understanding interfirm relations in mediation industries with special reference to the Nordic mobile communication industry', Industrial Marketing Management, Vol. 32, No. 5, pp.397-408.

Bengtsson, M. and Kock, S. (1999) 'Cooperation and competition in relationships between competitors in business networks', Journal of Business \& Industrial Marketing, Vol. 14, No. 3, pp.178-193.

Bengtsson, M. and Kock, S. (2000) 'Coopetition' in business networks - to cooperate and compete simultaneously’, Industrial Marketing Management, Vol. 29, No. 5, pp.411-426.

Bengtsson, M., Eriksson, J. and Wincent, J. (2010) 'Co-opetition dynamics - an outline for further inquiry’, Competitiveness Review, Vol. 20, No. 2, pp.194-214.

Brandenburger, A.M. and Nalebuff, B.J. (1996) Co-opetition, Currency/Doubleday, New York.

Brandt, R.L. (2011) One Click: Jeff Bezos and the Rise of Amazon.com, Portfolio, London.

Carroll, P. and Reader-Adams, A. (1994) Big Blues: The Unmaking of IBM, Crown Trade Paperbacks, New York.

Choi, P., Garcia, R. and Friedrich, C. (2010) 'The drivers for collective horizontal coopetition: a case study of screwcap initiatives in the international wine industry', International Journal of Strategic Business Alliances, Vol. 1, No. 3, pp.271-290.

Dagnino, G.B. (2009) 'Coopetition strategy. A new kind of dynamics for value creation', in Dagnino, G.B. and Rocco, E. (Eds.): Coopetition Strategy. Theory, Experiments and Cases, Routledge, London and New York.

Das, T.K. and Teng, B-S. (2000) 'A resource-based theory of strategic alliances', Journal of Management, Vol. 26, No. 1, pp.31-61.

Dowling, M.J., Roering, W.D., Carlin, B.A. and Wisnieski, J. (1996) 'Multifaceted relationships under coopetition: description and theory', Journal of Management Inquiry, Vol. 5, No. 2, pp.155-167.

Duntemann, J. and Pronk, R. (1994) Inside the PowerPC Revolution: The Inside Story Behind the Chips, Software, and Machines That Are Changing the Computer Industry, Coriolis Group Books, Albany, NY.

Dussauge, P., Garrette, B. and Mitchell, W. (2000) 'Learning from competing partners: outcomes and durations of scale and link alliances in Europe, North America and Asia', Strategic Management Journal, Vol. 21, No. 2, pp.99-126.

Gnyawali, D.R. and Madhavan, R. (2001) 'Cooperative networks and competitive dynamics: a structural embeddedness perspective', Academy of Management Review, Vol. 26, No. 3, pp.431-445.

Gnyawali, D.R. and Park, B-J. (2011) 'Co-opetition between giants: collaboration with competitors for technological innovation', Research Policy, Vol. 40, No. 6, pp.650-663.

Gnyawali, D.R., He, J. and Madhavan, R. (2006) 'Impact of co-opetition on firm competitive behavior: an empirical investigation', Journal of Management, Vol. 32, No. 4, pp.507-530.

Gnyawali, D.R., He, J. and Madhavan, R. (2008) 'Coopetition, promises and challenges', in Wankel, C. (Ed.): 21st Century Management: A Reference Handbook, pp.386-398, Sage, Thousand Oaks, CA.

Gomes-Casseres, B. (1994) 'Group versus group: how alliance networks compete', Harvard Business Review, Vol. 72, No. 4, pp.62-71.

Gueguen, G. (2009) 'Coopetition in business ecosystems in the information technology sector: the example of intelligent mobile terminals', International Journal of Entrepreneurship and Small Business, Vol. 8, No. 1, pp.135-153.

Gulati, R.N., Nohria, N. and Zaheer, A. (2000) 'Strategic networks', Strategic Management Journal, Vol. 21, No. 3, pp.203-215.

Iansiti, M. and Levien, M. (2004) 'Strategy as ecology', Harvard Business Review, Vol. 82, No. 3, pp.68-78.

Klir, G.J. (1991) Facets of Systems Science, Plenum, New York. 
Kothandaraman, P. and Wilson, D.T. (2001) 'The future of competition - value-creating networks', Industrial Marketing Management, Vol. 30, No. 4, pp.379-389.

Lado, A.A., Boyd, N.G. and Hanlon, S.C. (1997) 'Competition, cooperation, and the search for economic rents: a syncretic model', Academy of Management Review, Vol. 22, No. 1, pp.110-141.

Lane, D.C. (2008) 'The emergence and use of diagramming in system dynamics: a critical account', Systems Research and Behavioral Science, Vol. 25, No. 1, pp.3-23.

Larkin, J.H. and Simon, H.A. (1987) 'Why a diagram is (sometimes) worth ten thousand words', Cognitive Science, Vol. 11, No. 1, pp.65-100.

Levy, S. (2011) 'Jeff Bezos owns the web in more ways you think', Wired, December 2011.

M'Chirgui, Z. (2005) 'Smart card industry: a technological system', Technovation, Vol. 25, No. 8, pp.929-938.

Mariani, M. (2007) 'Coopetition as an emergent strategy', International Studies of Management \& Organization, Vol. 37, No. 2, pp.97-126.

Mingers, J. and Rosenhead, J. (2004) 'Problem structuring methods in action', European Journal of Operational Research, Vol. 152, No. 3, pp.530-554.

Möller, K. and Rajala, R. (2007) 'Rise of strategic nets - new modes of value creation', Industrial Marketing Management, Vol. 36, No. 7, pp.895-908.

Möller, K. and Svahn, S. (2006) 'Role of knowledge in value creation in business nets', Journal of Management Studies, Vol. 43, No. 5, pp.985-1007.

Padula, G. and Dagnino, G.B. (2007) 'Untangling the rise of coopetition. The intrusion of competition in a cooperative game structure', International Studies of Management \& Organization, Vol. 37, No. 2, pp.32-52.

Pidd, M. (2003) Tools for Thinking: Modelling in Management Science, John Wiley \& Sons Ltd., Chichester.

Pynnönen, M., Ritala, P. and Hallikas, J. (2011) 'The new meaning of customer value: a systemic perspective', Journal of Business Strategy, Vol. 32, No. 1, pp.51-57.

Ritala, P. (2012) 'Coopetition strategy - when is it successful? Empirical evidence on innovation and market performance', British Journal of Management, Vol. 23, No. 3, pp.307-324.

Ritala, P. and Hallikas, J. (2012) 'Network position of a firm and the tendency to collaborate with competitors - a structural embeddedness perspective', International Journal of Strategic Business Alliances, Vol. 2, No. 4, pp.307-328.

Ritala, P. and Hurmelinna-Laukkanen, P. (2009) 'What's in it for me? Creating and appropriating value in innovation-related coopetition', Technovation, Vol. 29, No. 12, pp.819-828.

Rosenhead, J. and Mingers, J. (2001) Rational Analysis for a Problematic World Revisited, John Wiley and Sons, Chichester.

Rusko, R. (2011) 'Exploring the concept of coopetition: a typology for the strategic moves of the Finnish forest industry', Industrial Marketing Management, Vol. 40, No. 2, pp.311-320.

Simon, H.A. (1992) 'Decision making and problem solving', in Zey, M. (Ed.): Decision Making, Alternatives to Rational Choice Models, pp.32-52, SAGE Publications, London.

Stabell, C.B. and Fjeldstad, Ø.D. (1998) 'Configuring value for competitive advantage: on chains, shops, and networks’, Strategic Management Journal, Vol. 19, No. 5, pp.413-437.

Tufte, E.R. (1990) Envisioning Information, Graphics Press, Cheshire, CT.

van Heck, E. and Vervest, P. (2007) 'Smart business networks: how the network wins', Communications of the ACM, Vol. 50, No. 6, pp.29-37.

Vanhaverbeke, W. and Noorderhaven, N.G. (2001) 'Competition between alliance blocks: the case of the RISC microprocessor technology', Organization Studies, Vol. 22, No. 1, pp.1-30.

Walley, K. (2007) 'Coopetition - an introduction to the subject and an agenda for research', International Studies of Management \& Organization, Vol. 37, No. 1, pp.11-31. 
Wegmann, A. (2003) 'On the systemic enterprise architecture methodology (SEAM)', Paper presented at the International Conference on Enterprise Information Systems, Angers, France. Yin, R. (2003) Case Study Research: Design and Methods, 3rd ed., Sage, Thousand Oaks, CA. 